\title{
Improving efficiency of organic photovoltaic cells with pentacene-doped CuPc layer
}

\author{
Wei-Bing Chen, Hai-Feng Xiang, Zong-Xiang Xu, Bei-Ping Yan, \\ V. A. L. Roy, and Chi-Ming Che a) \\ Department of Chemistry and HKU-CAS Joint Laboratory on New Materials, The University of Hong \\ Kong, Pokfulam Road, Honkong Special Administrative Region, China \\ Pui-To Lai \\ Department of Electrical \& Electronic Engineering, The University of Hong Kong, Pokfulam Road, \\ Honkong Special Administrative Region, China
}

(Received 17 September 2007; accepted 17 October 2007; published online 6 November 2007)

\begin{abstract}
We have fabricated efficient heterojunction organic photovoltaic (OPV) cells based on pentacene-doped copper(II) phthalocyanine $(\mathrm{CuPc})$ layer as donor and fullerene (C60) layer as acceptor. The power conversion efficiency of $4 \%$ pentacene-doped CuPc/C60 OPV cell $(3.06 \%)$ is increased by $77 \%$ compared with that of the standard CuPc/C60 OPV cell $(1.73 \%)$. The efficiency improvement can be attributed to the higher carrier mobility instead of the stronger photon absorption of the pentacene-doped CuPc layer. (C) 2007 American Institute of Physics.
\end{abstract}

[DOI: 10.1063/1.2806195]

External quantum efficiency $\left(\eta_{\mathrm{EQE}}\right)$ of organic photovoltaic $(\mathrm{OPV})$ cells is defined as $\eta_{\mathrm{EQE}}=\eta_{A} \times \eta_{\mathrm{ED}} \times \eta_{\mathrm{CC}}$. Here, $\eta_{A}, \eta_{\mathrm{ED}}$, and $\eta_{\mathrm{CC}}$ are absorption efficiency, exciton diffusion efficiency, and charge collection efficiency at the device electrodes, respectively. ${ }^{1-3}$ Absorption efficiency of incident photons primarily relates to the thickness of photoactive layers, ${ }^{4}$ and exciton diffusion efficiency is decided by both exciton diffusion length and the thickness of photoactive layers. Exciton diffusion length limits the thickness of the photoactive layer. ${ }^{5,6}$ The fraction of photogenerated excitons that reaches the donor/acceptor interface before recombining can dissociate into free charge carriers with a high yield. ${ }^{1}$ To date, much attention has been focused on increasing $\eta_{A}$ and $\eta_{\mathrm{ED}}$ to improve the external quantum efficiency and power conversion efficiency $\left(\eta_{P}\right)$. Recently, many smart device configurations have been invented to improve the $\eta_{P}$ of OPV cells. Bulk heterojunction $(\mathrm{HJ})$ structure is a useful means to increase the exciton diffusion efficiency. ${ }^{7-9} \quad \eta_{P}$ above $5 \%$ was achieved in tandem ${ }^{10,11}$ and rubrene-doped OPV cells. ${ }^{4}$

Usually, it is assumed that $\eta_{\mathrm{CC}}$ is about $100 \%$ under short-circuit conditions in the common HJ OPV structure. ${ }^{12}$ In fact, $\eta_{\mathrm{CC}}$ depends on the carrier mobility and hardly approaches $100 \%$. Generally, the carrier mobility of organic materials is lower than that of silicon. Copper(II) phthalocyanine $(\mathrm{CuPc})$ and fullerene $\left(\mathrm{C}_{60}\right)$ are widely used in OPV cells as donor and acceptor, respectively. However, the carrier mobility of $\mathrm{CuPc}\left(\sim 10^{-3} \mathrm{~cm}^{2} / \mathrm{V} \mathrm{s}\right)$ (Ref. 13) is much lower than that of $\mathrm{C}_{60}\left(\sim 0.5 \mathrm{~cm}^{2} / \mathrm{V} \mathrm{s}\right)$ at room temperature. ${ }^{14}$ This imbalance of carrier mobility between acceptor and donor can seriously affect the carrier collection efficiency.

Doping technology is widely used in OPV cells to improve their performance. ${ }^{15,16}$ In this study, considering the imbalance of carrier mobility between $\mathrm{CuPc}$ and $\mathrm{C}_{60}$, we doped pentacene into $\mathrm{CuPc}$ to improve the carrier mobility of $\mathrm{CuPc}$ and thus the performance of OPV cells. Pentacene is one of few organic semiconductors, which has high fieldeffect carrier mobility in thin film comparable to amorphous

\footnotetext{
a) Author to whom correspondence should be addressed. Electronic mail: cmche@hku.hk
}

silicon. ${ }^{17}$ Doping a high carrier mobility material in the OPV cell is expected to balance the carrier mobility of the acceptor and donor and thus improve the carrier collection efficiency. In this work, by doping pentacene into $\mathrm{CuPc}$, both short-circuit current density $\left(J_{\mathrm{SC}}\right)$ and fill factor $(\mathrm{FF})$ of the OPV cell were increased, resulting in $a$ high $\eta_{P}$ of $3.06 \%$.

The HJ OPV cells were fabricated on precleaned glass substrates precoated with a $\sim 1500-\AA$-thick transparent, conducting patterned indium tin oxide (ITO) anode with a sheet resistance of $40 \Omega$ /sq. After solvent cleaning, the substrates were treated in an ultraviolet-ozone chamber. All organic and metal layers were grown at room temperature in high vacuum $\left(\sim 5 \times 10^{-6}\right.$ Torr $)$. The mixed layers were deposited by coevaporation from two separately controlled sources. A layer of bathocuproine (BCP) was deposited after the active layers as an exciton blocking layer. ${ }^{18}$ Finally, an $\mathrm{Al}$ cathode was deposited by thermal evaporation through a shadow mask with an active device area of $0.0867 \mathrm{~cm}^{2}$. Deposition rates were monitored with a quartz oscillating crystal and controlled to be $0.1-0.2 \mathrm{~nm} / \mathrm{s}$ for both organic and metal layers. The OPV cells were fabricated with structures as follows:

(1) Standard OPV cell: ITO/CuPc $(20 \mathrm{~nm}) / \mathrm{C}_{60}(60 \mathrm{~nm}) /$ $\mathrm{BCP}(8 \mathrm{~nm}) / \mathrm{Al}(80 \mathrm{~nm})$.

(2) Pentacene-doped CuPc OPV cell: ITO/pentacene: CuPc $(20 \mathrm{~nm}) / \mathrm{C}_{60}(60 \mathrm{~nm}) / \mathrm{BCP}(8 \mathrm{~nm}) / \mathrm{Al}(80 \mathrm{~nm})$.

All organic materials were used as purchased. The composition of mixed layers was based on molar ratio of pentacene versus pentacene and $\mathrm{CuPc}$ [pentacene/(pentacene $+\mathrm{CuPc})]$. Current density-voltage $(J-V)$ characteristics were measured in the dark and under AM 1.5 solar illumination at an intensity of $100 \mathrm{~mW} / \mathrm{cm}^{2}$ with an Oriel $150 \mathrm{~W}$ solar simulator using a programmable Oriel mode 69907 power source. The light intensity was measured with an Oriel radiant power meter. Absorption spectra of the mixed layers on ITO glass substrates were measured with a Perkin-Elmer Lambda 19 UV/vis spectrophotometer. The morphology of the mixed layers deposited on Si wafer was inspected by a LEO1530 scanning electron microscope instrument. On the 

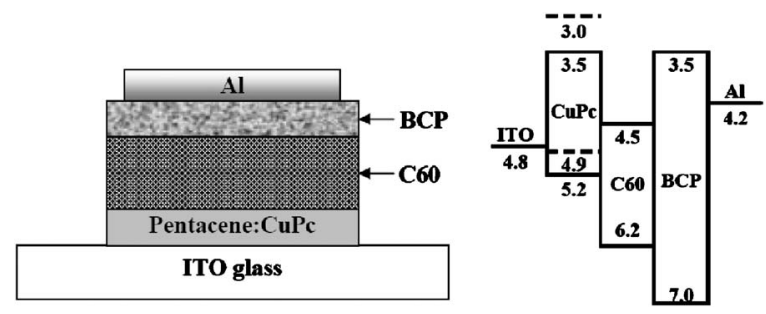

FIG. 1. Schematic structure (left) and energy level diagram (right, dash lines represent the energy levels of pentacene) of pentacene-doped CuPc OPV cell.

other hand, for the sake of the mobility measurement, the organic field-effect transistors were made on $\mathrm{Si}$ wafer with a 100-nm-thick $\mathrm{SiO}_{2}$ layer. $50 \mathrm{~nm}$ thickness organic layer was deposited by thermal evaporation at room temperature in high vacuum $\left(\sim 5 \times 10^{-6}\right.$ Torr $)$. The output and transfer characteristics of the devices were measured inside a $\mathrm{N}_{2}$ glovebox (Mbraun MB20G) equipped with a probe station connected to a semiconductor parameter analyzer (Keithley 4200 SCS). The field-effect charge mobility $\mu$ was estimated from the output characteristics in the saturation region where both drain voltage $\left(V_{d s}\right)$ and gate voltage $\left(V_{g}\right)$ were $-40 \mathrm{~V}$, according to the equation $I_{d s}=(W / 2 L) C_{i} \mu\left(V_{g}-V_{t}\right)^{2}$ (where $W=$ channel width, $L=$ channel length, $C_{i}=$ capacitance of insulating $\mathrm{SiO}_{2}$ layer, and $V_{t}=$ threshold voltage).

The schematic photovoltaic cell structure and a used organic materials energy levels diagram are shown in Fig. 1. Organic material energy levels are extracted from the literatures. ${ }^{18,19}$ The photovoltaic response for the pentacenedoped $\mathrm{CuPc}$ OPV cell as a function of pentacene concentration in the mixed layer is depicted in Fig. 2. Under illumination, the standard device has a $J_{\mathrm{SC}}$ of $7.75 \mathrm{~mA} / \mathrm{cm}^{2}$, opencircuit voltage $\left(V_{\mathrm{OC}}\right)$ of $0.52 \mathrm{~V}, \mathrm{FF}$ of 0.43 , and $\eta_{P}$ of $1.73 \%$. $J_{\mathrm{SC}}, \mathrm{FF}$, and $\eta_{P}$ rapidly increase with pentacene concentration at low concentration. For the $4 \%$ pentacene-doped CuPc OPV cell, $J_{\mathrm{SC}}, V_{\mathrm{OC}}, \mathrm{FF}$ and $\eta_{P}$ reach up to $12.93 \mathrm{~mA} / \mathrm{cm}^{2}$, $0.52 \mathrm{~V}, 46 \%$, and $3.06 \%$, respectively. Its $J-V$ characteristic in the dark and under AM 1.5 solar illumination is shown in Fig. 2(c). The reported field-effect carrier mobilities for $\mathrm{CuPc}, \mathrm{C}_{60}$, and pentacene are $7 \times 10^{-3}, 0.5$, and $1.5 \mathrm{~cm}^{2} / \mathrm{V} \mathrm{s}$, respectively. ${ }^{13,14,20}$ In this work, we found that the carrier mobility of bottom-contact thin-film transistor with active layer of pure $\mathrm{CuPc}$, pentacene and $\mathrm{C}_{60}$ films, and $4 \%$ pentacene-doped $\mathrm{CuPc}$ film were $2.4 \times 10^{-4}, 0.35,8.5$ $\times 10^{-2}$, and $2.8 \times 10^{-3} \mathrm{~cm}^{2} / \mathrm{V} \mathrm{s}$, respectively. The mobility of the $4 \%$ pentacene-doped CuPc film is closer to $\mathrm{C}_{60}$ than that of $\mathrm{CuPc}$. Therefore, the doping technology can effectively improve the carriers (electron and hole) mobility balance and thus the photovoltaic performance.

Figures 3(a)-3(c) show the surface morphology of three different active layers grown on the Si substrate at the same conditions. Obviously, pure pentacene has good crystal and bigger crystal grains than pure $\mathrm{CuPc}$, thus higher holes mobility. For the mixture layer with $4 \%$ pentacene, pentacene doping results in bigger $\mathrm{CuPc}$ crystal grains compared with pure $\mathrm{CuPc}$, which leads to an improvement in mobility. ${ }^{21}$ Moreover, Fig. 3(a) shows that wormlike pentacene crystals randomly distribute in the $\mathrm{CuPc}$ mixture layer. The length of the pentacene crystals is about $200 \mathrm{~nm}$, much longer than the mixture thickness $(20 \mathrm{~nm})$. They can create lots of new percolation paths through pentacene crystals to electrodes,
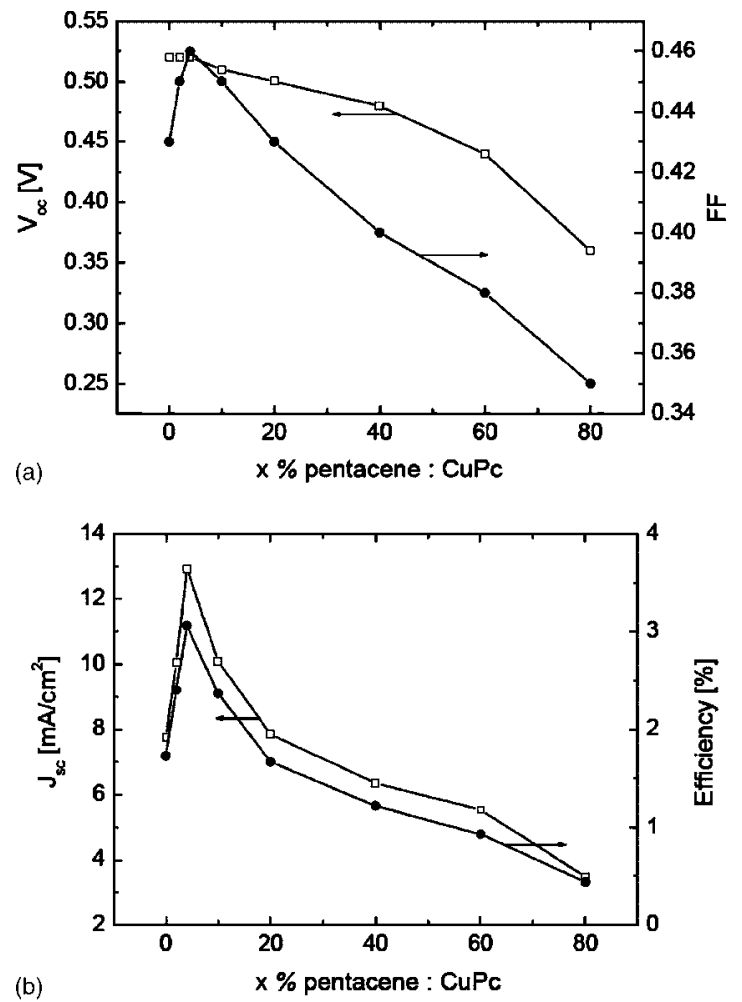

(b)

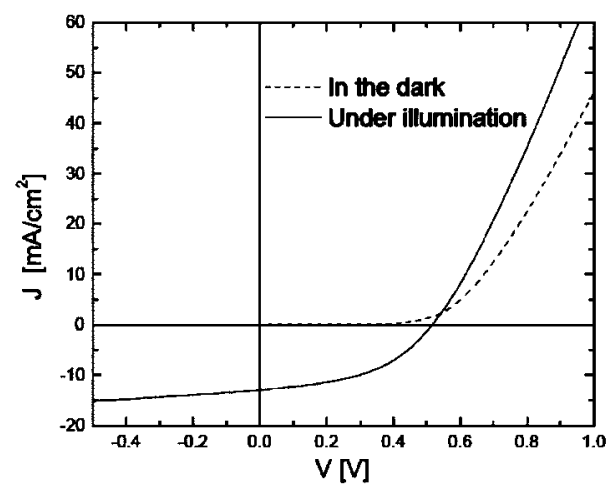

FIG. 2. Photovoltaic response of pentacene-doped $\mathrm{CuPc}$ OPV cell with different pentacene concentrations, (a) $V_{O C}$ and FF vs different pentacene concenerations, (b) $J_{S C}$ and efficiency vs different pentacene concentrations, and (c) $J-V$ characteristic of the doped CuPc OPV cell with $4 \%$ pentacene concentration.

similar to what has been tried using blends of carbon nanotubes or nanowaires. ${ }^{22}$ As the mobility of pentacene is higher than that of $\mathrm{CuPc}$, the percolation paths can effectively improve holes mobility in $\mathrm{CuPc}$ mixture layer and result in a better mobility balance between the CuPc mixture layer and the $\mathrm{C}_{60}$ layer, thus improving the device photovoltaic performance. This improvement mechanism is different from the reported work, ${ }^{4}$ where Chan et al. found that the photovoltaic performance could be remarkably improved by rubrene doping because rubrene had complementary absorption in the 450-550 nm range, but $\mathrm{CuPc}$ and $\mathrm{C}_{60}$ did not absorb. Further evidence can be seen from Fig. 4, where the absorption spectrum of $4 \%$ pentacene-doped CuPc layer is essentially similar to that of the pure CuPc layer, indicating that the photogenerated excitons are primarily produced by $\mathrm{CuPc}$ in the mixture. When the pentacene concentration is increased up to $40 \%$, the influence of pentacene on photon absorption becomes remarkable. As the pentacene has little contribution to photon absorption at a low concentration of $4 \%$, we atAIP license or copyright; see http://apl.aip.org/apl/copyright.jsp 


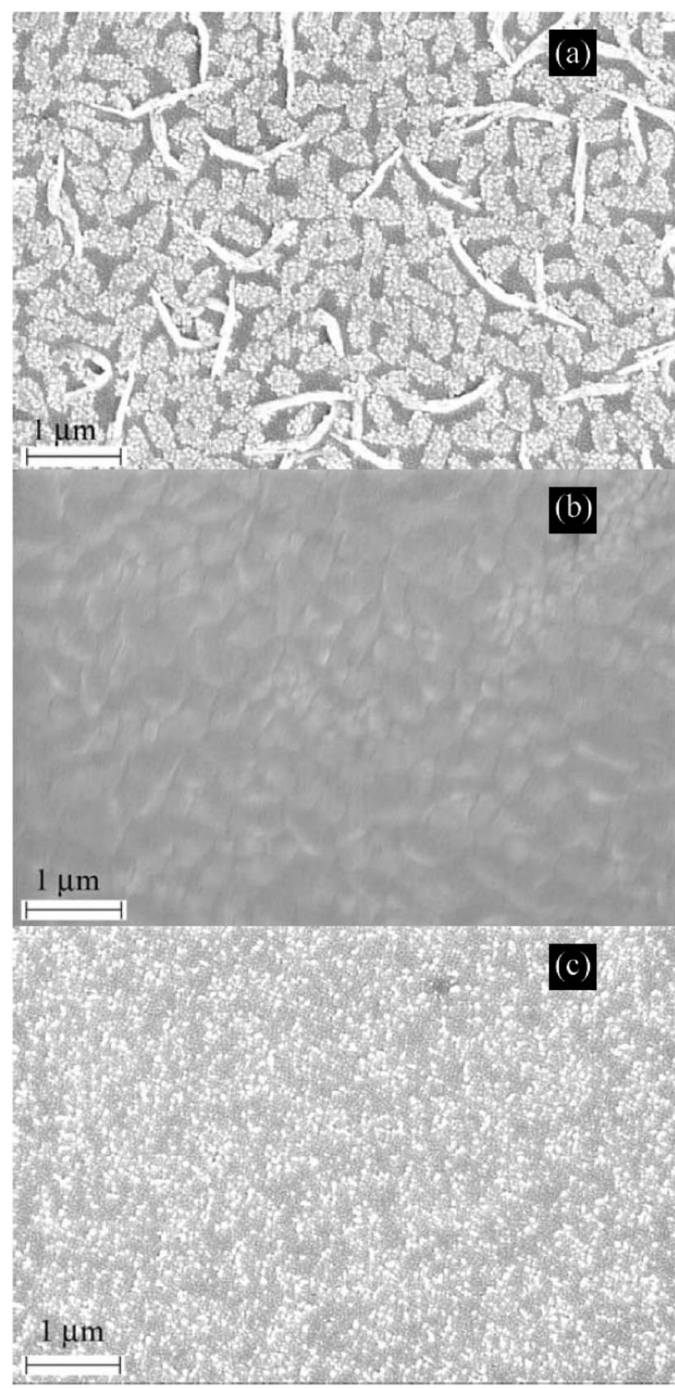

FIG. 3. Surface morphology of active layer grown on $\mathrm{Si}$ wafer, (a) $4 \%$ pentacene-doped $\mathrm{CuPc}$ film, (b) pure pentacene, and (c) pure CuPc.

tribute the photovoltaic improvement to the higher carrier mobility rather than the stronger photon absorption of the pentacene-doped CuPc layer. $J_{\mathrm{SC}}$ and FF decrease at high pentacene concentration, presumably due to the damage of $\mathrm{CuPc}$ crystal structure at high pentacene concentration.

As shown in Fig. 2(a), the $V_{\mathrm{OC}}$ of pentacene-doped CuPc OPV cells monotonically decreases with increasing pentacene concentration. The $V_{\mathrm{OC}}$ of bulk heterojunctions strongly

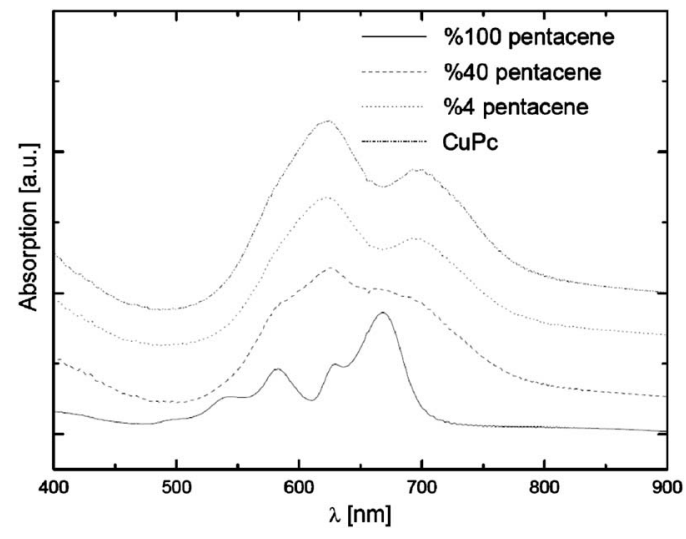

FIG. 4. Absorbance spectra of pure $\mathrm{CuPc}, 4 \%, 40 \%$ pentacene-doped $\mathrm{CuPc}$, and pure pentacene film. depends on the lowest unoccupied molecular orbital (LUMO) of the acceptor and the highest occupied molecular orbital (HOMO) of the donor. ${ }^{23,24}$ This decrease might be reasonably explained by the smaller energy gap between the HOMO of pentacene and LUMO of $\mathrm{C}_{60}$ than that between $\mathrm{CuPc}$ and $\mathrm{C}_{60}$ from Fig. 1.

In summary, we have demonstrated that the use of pentacene doping in CuPc OPV cell would lead to its performance improvement. The power conversion efficiency is optimized and can be up to $3.06 \%$ for $4 \%$ pentacene-doped $\mathrm{CuPc}$ OPV cell, much better than that of the standard CuPc OPV cell. Since pentacene has relatively high carrier mobility, we attribute this improvement to the higher carrier mobility rather than the stronger photon absorption of the pentacene-doped $\mathrm{CuPc}$ layer.

This work was supported by the Joint Research Scheme NSFC/RGC (N_HKU 742/04), the University Development Fund (Nanotechnology Research Institute, 00600009) of The University of Hong Kong, the Innovation Technology Fund (ITF), Strategic Theme on Nano-Biotechnology, the Strategic Theme on Organic Electronics, and RGC of HKSAR (Project No. HKU 7158/04E). We acknowledge Clover \& Sunic Systems Ltd. for their support with the fabrication system housed at The University of Hong Kong. We thank Mandy Liu and Dickey Ma for their help in substrate preparation.

${ }^{1}$ P. Peumans, A. Yakimov, and S. R. Forrest, J. Appl. Phys. 93, 3693 (2003).

${ }^{2}$ A. Moliton and J. M. Nunzi, Polym. Int. 55, 583 (2006).

${ }^{3}$ R. F. Salzman, J. Xue, B. P. Rand, A. Alexander, M. E. Thompson, and S. R. Forrest, Org. Electron. 6, 242 (2005).

${ }^{4}$ M. Y. Chan, S. L. Lai, M. K. Fung, C. S. Lee, and S. T. Lee, Appl. Phys. Lett. 90, 023504 (2007).

${ }^{5}$ Y. Shao and Y. Yang, Adv. Mater. (Weinheim, Ger.) 17, 2841 (2005).

${ }^{6}$ J. Xue, B. P. Rand, S. Uchida, and S. R. Forrest, Adv. Mater. (Weinheim, Ger.) 17, 66 (2005).

${ }^{7}$ P. Peumans, S. Uchida, and S. R. Forrest, Nature (London) 425, 158 (2003).

${ }^{8}$ S. Uchida, J. Xue, B. P. Rand, and S. R. Forrest, Appl. Phys. Lett. 84, 4218 (2004).

${ }^{9}$ P. Sullivan, S. Heutz, S. M. Schultes, and T. S. Jones, Appl. Phys. Lett. 84, 1210 (2004).

${ }^{10}$ J. Xue, S. Uchida, B. P. Band, and S. R. Forrest, Appl. Phys. Lett. 85, 5757 (2004).

${ }^{11}$ J. Drechsel, B. Männig, F. Kozlowshi, M. Pfeiffer, K. Leo, and H. Hoppe, Appl. Phys. Lett. 86, 244102 (2005).

${ }^{12}$ H. Hoppe and N. S. Sariciftci, J. Mater. Res. 19, 1924 (2004).

${ }^{13}$ Y. Terao, H. Sasabe, and C. Adachi, Appl. Phys. Lett. 90, 103515 (2007).

${ }^{14}$ S. Kobayashi, T. Takenobu, S. Mori, A. Fujiwara, and Y. Iwasa, Sci. Technol. Adv. Mater. 4, 371 (2003).

${ }^{15}$ M. Hiramoto, Y. Kishigami, and M. Yokoyama, Chem. Lett. 19, 119 (1990).

${ }^{16}$ Rudiono, F. Kaneko, and M. Takeuchi, Appl. Surf. Sci. 142, 598 (1999).

${ }^{17}$ A. K. Pandey, S. Dabos-Seignon, and J. M. Nunzi, Appl. Phys. Lett. 89, 113506 (2006).

${ }^{18}$ P. Peumans and S. R. Forrest, Appl. Phys. Lett. 79, 126 (2001).

${ }^{19}$ S. Yoo, B. Domercq, and B. Kippelen, Appl. Phys. Lett. 85, 5427 (2004).

${ }^{20}$ Y.-Y. Lin, D. J. Gundlach, S. F. Nelson, and T. N. Jackson, IEEE Electron Device Lett. 18, 606 (1997).

${ }^{21}$ S. J. Kang, M. Noh, D. S. Park, H. J. Kim, and C. N. Whang, J. Appl. Phys. 95, 2293 (2004).

${ }^{22}$ W. U. Huynh, J. J. Dittmer, and A. P. Alivisatos, Science 295, 2425 (2002).

${ }^{23}$ C. J. Brabec, A. Cravino, D. Meissner, N. S. Sariciftci, M. T. Rispens, L. Sanchez, J. C. Hummelen, and T. Fromherz, Thin Solid Films 403-404, 368 (2002).

${ }^{24}$ H. Kim, S.-H. Jin, H. Suh, and K. Lee, Proc. SPIE 5215, 111, 2004. 